\title{
Seleção de indicadores de paisagem para as áreas ambientais em assentamento rural
}

Os Assentamentos Rurais (ARs) são a materialização do processo de reforma agrária no Brasil, sendo caracterizados pela sua multifuncionalidade. Com relação à função ambiental, os ARs devem respeitar os dispositivos legais da Política Nacional do Meio Ambiente (PNMA), com a conservação das áreas de preservação permanente (PP) e de reserva legal (RL); áreas ambientais do AR. Desta forma, é de extrema importância a seleção e a utilização de indicadores para auxiliar na avaliação e monitoramento destas áreas em ARs, associando-se a Sistema de Informação Geográfica (SIG). Neste contexto, o objetivo deste estudo é selecionar indicadores de paisagens para as áreas ambientais em ARs, exemplificado no AR Rosa Luxemburgo II, em São Cristóvão, Sergipe. Após revisão bibliográfica, definiuse oito indicadores de paisagem da categoria 'Uso da Terra', associando-se a utilização de ferramentas de processamento digital de imagens e plataforma SIG Como principais resultados, têm-se que, no AR estudado, na fase de ordenamento espacial do AR, existe significativa omissão das áreas de PP; cerca de $61 \%$ e $48 \%$ das áreas ambientais e de RL, respectivamente, estão efetivamente ocupadas com vegetação nativa, necessitando a recomposição florestal das demais áreas ambientais, para a plena disponibilidade dos serviços ecossistêmicos; e, a existência da Assessoria Técnica, Social e Ambiental à Reforma Agrária (ATES) não representou ações ambientais de conservação e de proteção das áreas de PP e RL. Como conclusões, tem-se que os indicadores de paisagem, no modelo DPSIR, são importantes para a avaliação e o monitoramento das áreas ambientais em ARs, mostrando-se uma ferramenta efetiva para o planejamento e a gestão ambiental de ARs.

\section{Selection of landscape indicators for rural settlement environmental areas}

The Rural Settlements (RSs) are the materialization of the agrarian reform process in Brazil, characterized by their multifunctionality. Regarding the environmenta function, the RS must respect the legal provisions of the National Environmental Policy (NEP), in order to keep the permanent preservation areas (PPA) and legal reserve (LR); environmental areas of the RS. Therefore, it is extremely important to select and use indicators to assist in the evaluation and monitoring of these areas in RS, associating with the Geographic Information System (GIS). In this context, the objective of this study is to select landscape indicators for the environmental areas in RS, such as Rosa Luxemburg II Rural Settlement, in São Cristóvão, Sergipe. After a bibliographic review, eight landscape indicators of the 'Land Use' category were defined, associating the use of digital image processing tools and GIS platform. As the main results, there's a significant omission of PPA areas in the RS studied in the spatial ordering phase; about $61 \%$ and $48 \%$ of the environmental and LR areas, respectively, are effectively occupied with native vegetation, requiring the forestry recomposition of the other environmental areas, for the full availability of ecosystem services; and the existence of the Technical, Social and Environmental Advisory to Agrarian Reform did not represent environmental conservation and protection of the PP and RL areas. As a conclusion, the landscape indicators, in the DPSIR model, are important for the evaluation and monitoring of the environmental areas in ARs, proving to be an effective tool for the planning and environmental management of ARs.

Keywords: Environmental management; GIS; Agrarian Reform; Environment; Environmental Services.

Topic: Planejamento, Gestão e Políticas Públicas Ambientais

Reviewed anonymously in the process of blind peer.

Bruno Gomes Cunha (iD)

Universidade Federal de Viçosa, Brasil

http://lattes.cnpq.br/1275837338973534

http://orcid.org/0000-0002-2281-9370

pericia.agraria@gmail.com

\section{Alceu Pedrotti (id}

Universidade Federal de Sergipe, Brasil

http://lattes.cnpq.br/5022174893387665

http://orcid.org/0000-0003-3086-8399

alceupedrotti@gmail.com

Edson Magalhães Bastos Júnior

Universidade Federal de Sergipe, Brasil

http://lattes.cnpq.br/2104003119220085

http://orcid.org/0000-0001-9276-5403

arjunaself@gmail.com
Received: 10/04/2018

Approved: 24/05/2018

Ivana Silva Sobral (iD)

Instituto Nacional de Colonização e Reforma Agrária, Brasil

http://lattes.cnpq.br/2221246547084492

http://orcid.org/0000-0001-7435-2496

ivanasobral@hotmail.com
Referencing this:

CUNHA, B. G.; PEDROTTI, A.; BASTOS JÚNIOR, E. M.; SOBRAL, I. S.. Seleção de indicadores de paisagem para as áreas ambientais em assentamento rural. Revista Ibero Americana de Ciências Ambientais, v.9, n.4, p.326-335, 2018. DOI: http://doi.org/10.6008/CBPC21796858.2018 .004 .0026 


\section{INTRODUÇÃO}

Os Assentamentos Rurais (ARs) podem ser inicialmente definidos como novas unidades de produção que, no nível local ou regional, reordenam o sistema de propriedade e uso das terras, estabelecendo outros padrões sociais de produção agrícola e, por vezes, criam novas dinâmicas econômicas e sociais (DIAS, 2004), através da sua multifuncionalidade (YANBO et al., 2017). No Brasil, atualmente, existem 9.358 ARs, explorados por 974.545 famílias, ocupando uma área superior a 10\% do território nacional (INCRA, 2017). Estes ARs estão sob a gestão INCRA; órgão federal cuja missão prioritária é executar a reforma agrária e realizar o ordenamento fundiário no Brasil (ONDETTI, 2016).

Para o desenvolvimento sustentável destes novos empreendimentos rurais, e, consequentemente, para efetivação da Política Nacional de Reforma Agrária (PNRA), torna-se mister que os dispositivos legais da Política Nacional do Meio Ambiente (PNMA) sejam respeitados. Dentre os aludidos dispositivos, destaca-se a Lei $n^{\circ} 12.651 / 2012$, que dispõe sobre a proteção da vegetação nativa, sobretudo, as que estão situadas em áreas de preservação permanente (PP) e de reserva legal (RL); áreas ambientais institucionalizadas de proteção da natureza (CUNHA et al., 2008). Com a vigência desta lei, os imóveis rurais, inclusive os ARs, devem estar inseridos no Sistema de Cadastro Ambiental Rural (SICAR), para que estejam regularizados ambientalmente, podendo ainda, aderir ao Programa de Regularização Ambiental (PRA), ou ainda, ofertar Cotas de Reservas Ambientais (CRA) (BRASIL, 2012).

Essas áreas ambientais (PP+RL) são de suma importância para manutenção das funções ecológicas dos ecossistemas e para o funcionamento dos serviços ecossistêmicos (VILAR et al., 2012). Por conseguinte, sabe-se que os ARs alteram a dinâmica dos serviços ecossistêmicos na paisagem (CUNHA et al., 2015), facultando a sua adoção como unidade de planejamento, estudo e monitoramento dos recursos naturais (CUNHA et al., 2013). Considera-se como serviços ecossistêmicos, os bens e serviços provenientes dos ecossistemas (DAILY, 1997), tomados como bens públicos, tais como a regulação climática, a produção de alimentos e de recursos hídricos, habitat, dentre outros (PHILLIPS et al., 2005), e, que podem ser categorizados em serviços de suporte, de regulação, abastecimento e cultural (MEA, 2003).

Entende-se ser necessário o conhecimento do quantitativo e do estado de conservação destas áreas ambientais nos ARs, sendo possível através de indicadores ambientais (FREITAS et al., 2013), associando-se a ferramentas de geoprocessamento e Sistemas de Informações Geográficas (SIG) (COELHO et al., 2015; MENDES et al., 2016). Os indicadores ambientais são ferramentas para monitorar e avaliar a sustentabilidade (BRAMBILA et al., 2018), e, os indicadores de paisagem se apresentam como essenciais, funcionando como instrumento para avaliar as condições de usos e processos territoriais ligados à transformação das paisagens, fornecendo diretrizes para criação de estratégias que visam à proteção, gestão e inovação dos usos da terra (VOGHERA, 2011), sendo categorizados em: Econômico; Ecológico; Percepção Visual; Usos da Terra; Histórico e Cultural (CASSATELA et al., 2011).

Dentre os diversos modelos de análise dos indicadores, tem-se o modelo DPSIR (Forças motrizes, Pressões, Estado, Impacto e Respostas), que deriva do modelo PER (Pressão-Estado-Resposta) e foi adaptado 
pela Organização para Cooperação Econômica e Desenvolvimento (OCDE) (SVARSTAD et al., 2008). De acordo com a estrutura deste modelo, os vários aspectos dos desenvolvimentos sociais e econômicos são as forças motrizes que exercem pressão no meio ambiente (positiva ou negativa). Essas conduzem às mudanças no seu estado, que, por sua vez, conduzem aos impactos na saúde humana, nos ecossistemas e nos recursos naturais, resultando em resposta da sociedade direcionada para forças motrizes, pressões e/ou estado, ou até diretamente no impacto (NIEMEIJER et al., 2008).

Este modelo reforça a interação entre as causas dos problemas ambientais, os impactos e as respostas da sociedade, de uma forma integrada (LIRA et al., 2008), percebendo-se as ligações existentes entre o ambiente, através dos indicadores ambientais, e a sociedade, através do desempenho ambiental (KEMERICH et al., 2014). Assim, neste artigo, busca-se selecionar indicadores de paisagem para as áreas ambientais (PP e RL) em AR, em plataforma SIG, identificando-se nas suas especificidades, os aspectos potenciais e limitantes desta potencial ferramenta, através de estudo de caso.

\section{METODOLOGIA}

\section{Caracterização da Área de Estudo}

Para realização deste estudo, selecionou-se o Assentamento Rural Rosa Luxemburgo II, localizado no município de São Cristóvão, região fisiográfica do Litoral Sergipano, no Estado de Sergipe (IBGE, 1990), conforme Figura 1.
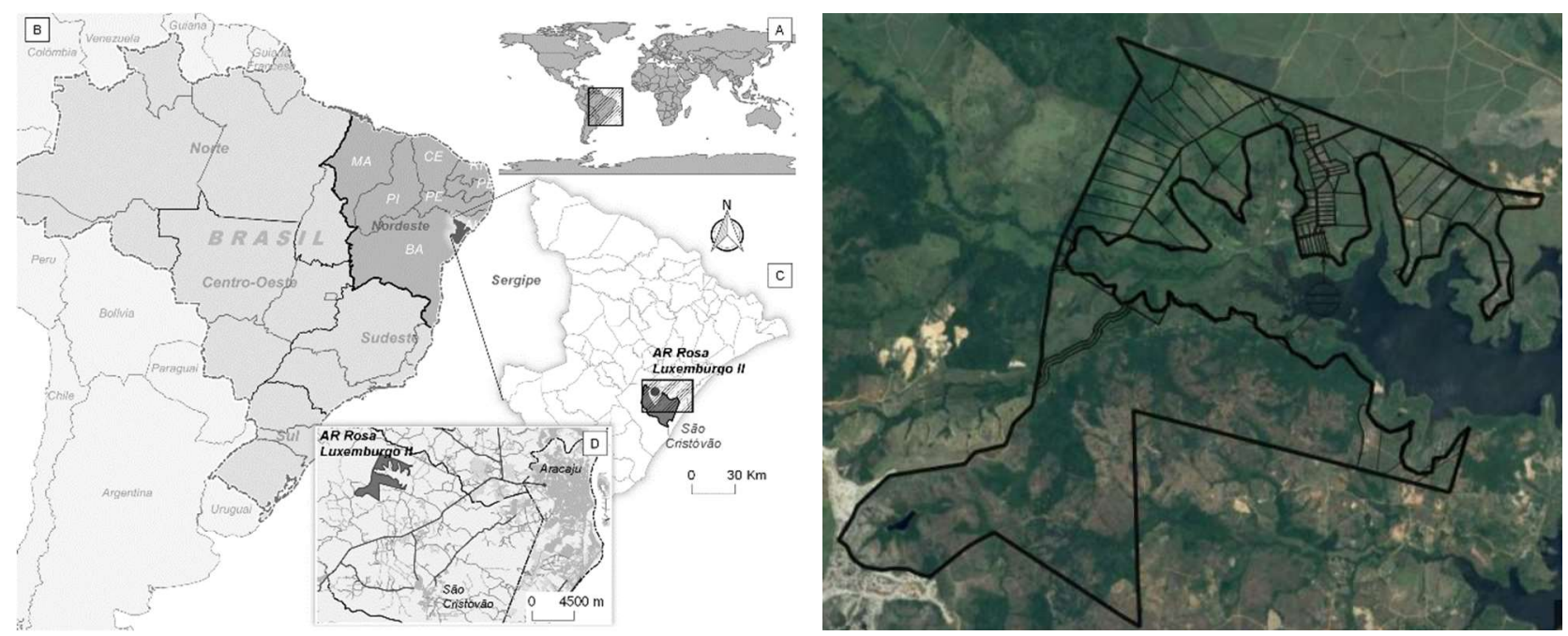

Figura 1: Localização e ordenamento espacial do AR Rosa Luxemburgo II. Fonte: Sergipe (2012); INCRA (2009).

O AR Rosa Luxemburgo II é um Projeto de Assentamento Federal (PA), criado em 2009, através da desapropriação da Fazenda Poxim, sob gestão do INCRA, tendo inicialmente, área de 1.377,65 ha e capacidade de assentamento para 50 famílias. À época da desapropriação, buscando-se o aumento e a regularização da vazão explorável do rio Poxim-Açu; afluente do Rio Poxim, o INCRA concedeu parte da área desapropriada para a Companhia de Saneamento de Sergipe - DESO, a fim de se constituir a área do reservatório e de segurança da barragem Jaime Umbelino de Souza. Atualmente, o AR Rosa Luxemburgo II possui capacidade de assentamento para 41 famílias, com área de 923,51 ha (INCRA, 2009). 
Este AR faz limite com o reservatório da barragem Jaime Umbelino de Souza ${ }^{1}$, inserido na bacia hidrográfica do rio Poxim (SERGIPE, 2012); situada entre as coordenadas geográficas de 1055’00” e $10^{\circ} 45^{\prime} 00^{\prime \prime}$ Latitude Sul e $37^{\circ} 05^{\prime} 00^{\prime \prime}$ e $37^{\circ} 22^{\prime} 00^{\prime \prime}$ Longitude Oeste, dentro da Bacia do rio Sergipe, a mais importante do Estado de Sergipe (COSTA et al., 2014). Apresenta clima do tipo As, de acordo com a classificação de Köppen (tropical chuvoso com verão seco). O período chuvoso ocorre entre os meses de abril e agosto, com precipitação média anual de $1.200 \mathrm{~mm}$, temperatura média de 25,5 ํC e umidade relativa do ar média de 75\% (FERREIRA et al., 2011).

\section{Seleção dos Indicadores}

Para a escolha dos indicadores, pautou-se na proposta apresentada por Voguera (2011), selecionando-se oito indicadores da categoria 'Usos da Terra', distribuídos nas subcategorias: Paisagens Degradadas e/ou Paisagens sob Pressão (Pressão), Paisagem Protegida (Estado), Ações de Valorização (Impacto), e, Eficácia de Ações do Planejamento Visando à Paisagem (Resposta), conforme descrito na Tabela 1.

Tabela 1: Categoria 'Usos da Terra' - subcategorias e indicadores selecionados.

\begin{tabular}{|c|c|c|c|c|}
\hline Subcategoria & Indicadores & Descrição & Unidade & Forma de Cálculo \\
\hline \multirow[t]{2}{*}{$\begin{array}{l}\text { Paisagens Degradadas } \\
\text { e /ou Paisagens Sob } \\
\text { Pressão (Pressão) }\end{array}$} & $\begin{array}{l}\text { Área de Reserva Legal } \\
\text { (RL) } \\
\text { Sob Pressão }\end{array}$ & $\begin{array}{l}\text { Percentual da área de } \mathrm{RL} \text { sem } \\
\text { vegetação nativa }\end{array}$ & $\%$ & $\begin{array}{l}\text { (Área de } R L_{\text {sem vegetação nativa }} \\
\text { x 100)/(Área total } \text { de } R L)\end{array}$ \\
\hline & $\begin{array}{l}\text { Área de Preservação } \\
\text { Permanente (PP) Sob } \\
\text { Pressão }\end{array}$ & $\begin{array}{l}\text { Percentual da área de PP sem } \\
\text { vegetação nativa }\end{array}$ & $\%$ & $\begin{array}{l}\text { (Área de } \mathrm{PP}_{\text {sem vegetação }} \\
\text { nativa } \times 100) /(\text { Área } \\
\text { PP) }\end{array}$ \\
\hline \multirow[t]{4}{*}{$\begin{array}{l}\text { Proteção da Paisagem } \\
\text { (Estado) }\end{array}$} & $\begin{array}{l}\text { Regularidade } \\
\text { Ambiental }\end{array}$ & AR inscrito no SICAR & $*$ & $\begin{array}{ll}1 . & \text { Sim } \\
2 . & \text { Não }\end{array}$ \\
\hline & Área de PP & $\begin{array}{l}\text { Percentual da área do AR } \\
\text { classificada como de PP }\end{array}$ & $\%$ & $\begin{array}{llll}\text { (Área } & \text { detal } & \text { PP } & x \\
\text { 100)/(Área total } & \text { do AR) } & \end{array}$ \\
\hline & Área de $R L$ & $\begin{array}{l}\text { Percentual da área do } \mathrm{AR} \\
\text { classificada como RL }\end{array}$ & $\%$ & $\begin{array}{l}\text { (Área total de RL)/Áreatotal } \\
\text { do } A R) \times 100\end{array}$ \\
\hline & $\begin{array}{l}\text { Área de Vegetação } \\
\text { Nativa }\end{array}$ & $\begin{array}{l}\text { Percentual da área ambiental } \\
\text { com vegetação nativa }\end{array}$ & $\%$ & $\begin{array}{ll}\text { (Área } & \text { Ambiental }\left.\right|_{\text {com }} \\
\text { vegetação } \quad \text { nativa } & \times \\
100) /(\text { Área } & \\
\text { Ambiental } & \end{array}$ \\
\hline $\begin{array}{l}\text { Ações de Valorização } \\
\text { (Impacto) }\end{array}$ & Ações Ambientais & $\begin{array}{l}N^{\circ} \text { de ações ambientais (cursos, } \\
\text { produção e plantio de mudas, } \\
\text { cercamento)/ano }\end{array}$ & $\begin{array}{l}\text { No }^{\circ} \text { de } \\
\text { ações/ano }\end{array}$ & $\begin{array}{l}N^{\circ} \text { de ações ambientais } \\
\text { realizadas/ano }\end{array}$ \\
\hline $\begin{array}{l}\text { Eficácia de Ações do } \\
\text { Planejamento } \\
\text { (Resposta) }\end{array}$ & Proteção & $\begin{array}{l}\text { Percentual de cerca planejada e } \\
\text { instalada para isolamento da } \\
\text { área ambiental }\end{array}$ & $\%$ & $\begin{array}{l}\text { (Cerca instalada } x \\
100) /(\text { Cerca planejada) }\end{array}$ \\
\hline
\end{tabular}

Fonte: Adaptado de Voghera (2011).

Na seleção dos indicadores, buscou-se abranger as principais condições e interfaces que as áreas ambientais do AR estão inseridas e submetidas, priorizando-se indicadores métricos da paisagem (BORGOGNO-MONDINO et al., 2015), obtidos através de ferramentas de geoprocessamento, enquanto os qualitativos, aqueles de fácil consulta na base de dados do INCRA.

\footnotetext{
${ }^{1}$ Esta barragem está situada no rio Poxim-Açu, na bacia hidrográfica do Rio Poxim, com área de inundação de $5,2 \mathrm{~km}{ }^{2}$ e capacidade de $3,2 \times 10^{7} \mathrm{~m}^{3}$ de armazenamento, beneficiando cerca de 800 mil pessoas residentes na região metropolitana da capital do Estado de Sergipe (NEVES et al., 2016).
} 


\section{Coleta e Análise das Informações}

Para a coleta dos dados primários, foram realizadas caminhadas transversais no AR, buscando-se analisar o estado de conservação das áreas de PP e de RL. No caso dos dados secundários, buscou-se informações junto aos processos administrativos, na base cartográfica do INCRA, bem como no Atlas Digital sobre Recursos de Sergipe (SERGIPE, 2012). E, para a obtenção das variáveis utilizadas no cálculo dos indicadores, utilizou-se de processamento digital de imagem (ano 2015), obtida gratuitamente do Google Earth, com o uso do software QGIS 2.18.14 Las Palmas (QGIS, 2017), licenciado sob a 'GNU General Public License', conforme etapas apresentadas na Figura 2.

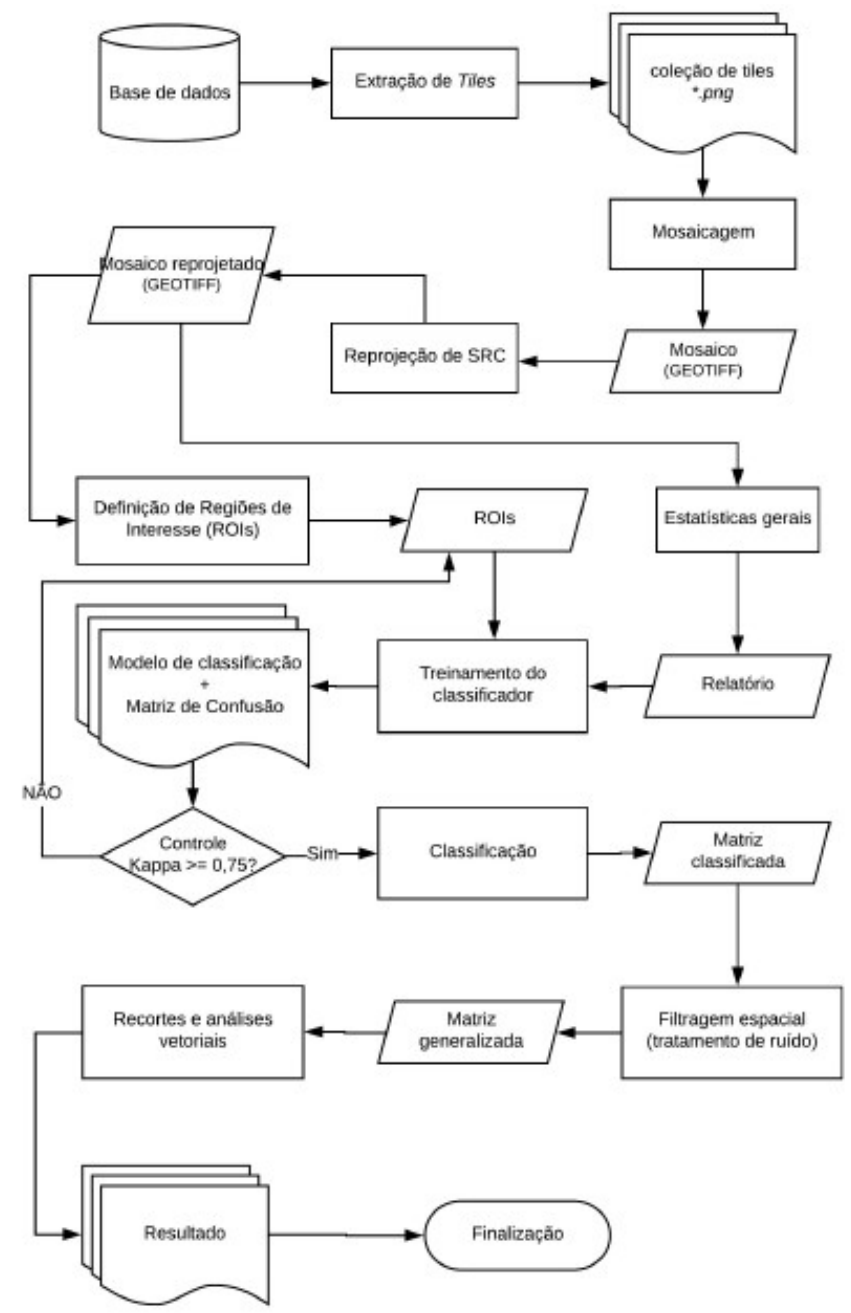

Figura 2: Fluxograma utilizado para o processamento digital de imagem.

Aquisição de imagem: Para a obtenção de uma matriz para classificação, fez-se a extração e junção (moisaicagem) de vector tiles (geoserviços Google), com escala de visualização de 1:5.000. Após, realizou-se a reprojeção de SRC (UTM 24 S SIRGAS 2000), resultando no mosaico reprojetado.

Classificação supervisionada de imagem: Para a interpretação da imagem, a partir de métodos de reconhecimento de padrões, definiu-se feições de interesse (vegetação, solo descoberto, corpo d'água e cultivo agropecuário), através de fotointerpretação e trabalhos de campo (coleta de pontos de treinamento georreferenciados). No treinamento do classificador semiautomático, utilizou-se a função SVM linear kernel, implementada na plataforma otb-monteverdi toolbox, tendo como controle o Índice de Kappa $\geq 0,75$; que 
indica boa concordância (LANDIS et al., 1977). Na sequência gerou-se as estatísticas básicas da matriz, e, a classificação da imagem (matriz classificada). Por fim, realizou-se a filtragem espacial, para o tratamento de ruídos (pixels isolados).

Recorte e análise vetorial: Converteu-se a imagem de raster para vetor, com a mudança do tipo de geometria (multipolígono para polígono). Por fim, recortou-se as áreas de interesse (áreas ambientais), calculando a área e o perímetro dos polígonos componentes de cada feição (Figura 3).

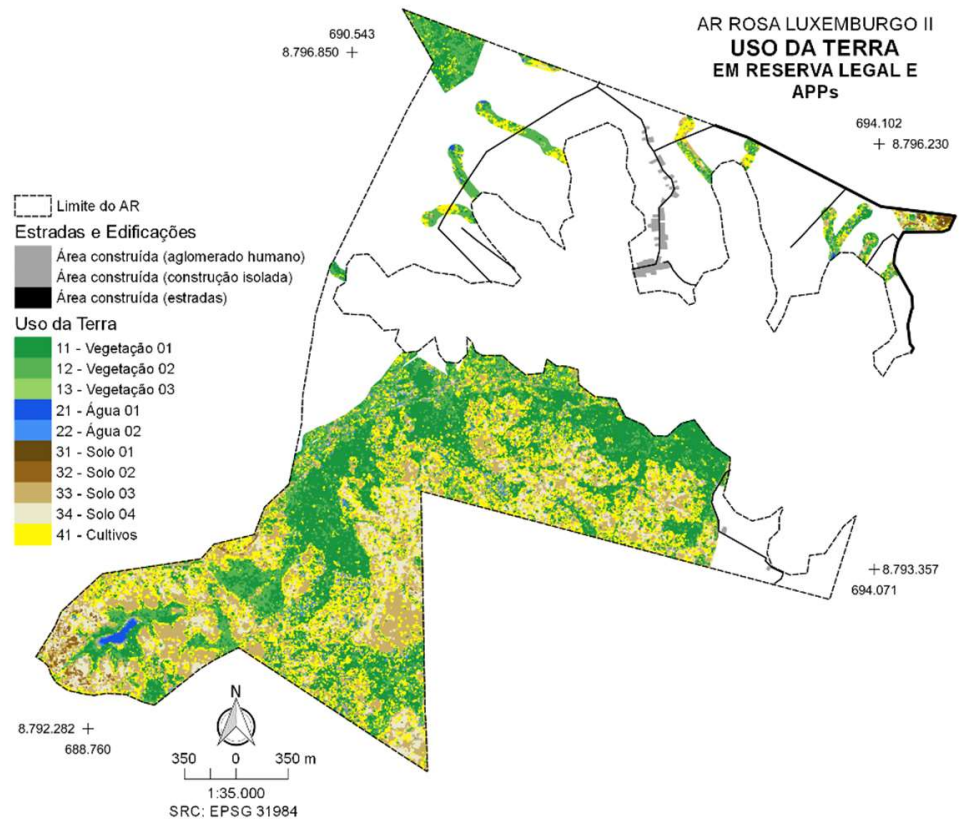

Figura 3: Resultado da classificação supervisionada das áreas ambientais do AR Rosa Luxemburgo II.

\section{RESULTADOS E DISCUSSÃO}

Na subcategoria 'Paisagens Degradadas e/ou Paisagem Sob Pressão', avalia-se o quanto as áreas ambientais estão sob pressão. Desta forma, conforme Tabela 2, o indicador Área de Reserva Legal (RL) Sob Pressão mostra que $51,5 \%$ da área delimitada para RL se encontra com solos descobertos ou sob cultivo agropecuário (culturas ou pastagem). Este percentual pode ser explicado pelo elevado percentual de área do AR destinado para RL (57,7\% do AR) (INCRA, 2009), e, pelo uso antrópico anterior à implantação do AR, sendo que parte das áreas de RL ainda permanecem degradadas (solos descobertos), pois são constituídas, em sua maioria, por solos ácidos, pedregosos e com baixa fertilidade natural, a exemplo dos Argissolos Vermelho Amarelos distróficos (INCRA, 2005); situação que dificulta a regeneração natural.

Tabela 2: Valores dos indicadores de paisagem no AR Rosa Luxemburgo II.

\begin{tabular}{|l|l|l|}
\hline Subcategoria & Indicadores & Valor \\
\hline Paisagens Degradadas e /ou Paisagens Sob Pressão (Pressão) & Área de Reserva Legal (RL) Sob Pressão & $51,5 \%$ \\
\hline & Área PP Sob Pressão & $43,8 \%$ \\
\hline Proteção da Paisagem (Estado) & Regularidade Ambiental & Sim \\
\hline & Área de PP & $3,2 \%$ \\
\hline & Área de RL & $57,7 \%$ \\
\hline & Área de Vegetação Nativa & $48,1 \%$ \\
\hline Ações de Valorização (Impacto) & Ações Ambientais & 0 \\
\hline Eficácia de Ações do Planejamento (Resposta) & Proteção & 0 \\
\hline
\end{tabular}


No indicador Área de Preservação Permanente (PP) Sob Pressão, exceto as áreas de PP inseridas nas de RL (não contabilizadas), 43,8\% das áreas de PP estão sob cultivo ou com solos descobertos, ou seja, a princípio, tem-se um conflito de uso do solo (SILVA et al., 2010). Estas áreas estão no entorno ou no interior das parcelas agrícolas, e, caso não sejam consideradas áreas consolidadas (BRASIL, 2012), medidas proibitivas e de conscientização devem ser realizadas pelo INCRA e/ou órgão ambiental junto aos agricultores familiares. No tocante à subcategoria 'Proteção da Paisagem', no indicador Regularidade Ambiental, observa-se que o AR está inserido no SICAR, atendendo a legislação ambiental (BRASIL, 2012). Quanto ao indicador Área de $P P$, resgata-se que, no momento da fiscalização, em 2005, no Laudo Agronômico de Fiscalização (INCRA, 2005), as áreas de PP foram estratificadas (Tabela 3), representando 15,3\% da área do imóvel fiscalizado.

Tabela 3: Distribuição das áreas de PP no AR Rosa Luxemburgo II, São Cristóvão, SE.

\begin{tabular}{|l|l|l|l|}
\hline Descrição & $\begin{array}{l}\text { Laudo de Fiscalização } \\
(2005)\end{array}$ & $\begin{array}{l}\text { Ordenamento Espacial do AR } \\
(2009)\end{array}$ & $\begin{array}{l}\text { Pesquisa } \\
(2015)\end{array}$ \\
\hline Ao longo de cursos d'água com menos de $10 \mathrm{~m}$ & $\mathbf{7 6 , 5 3 \mathrm { ha }}$ & $10,86 \mathrm{ha}$ & $\mathbf{2 2 , 5} \mathrm{ha}$ \\
\hline $\begin{array}{l}\text { Em encostas ou partes destas com declividade } \\
\text { superior a 45 }\end{array}$ & $134,04 \mathrm{ha}$ & - & - \\
\hline Nas nascentes & - & - & $6,7 \mathrm{ha}$ \\
\hline TOTAL & $\mathbf{2 1 0 , 5 7}$ ha & $\mathbf{1 0 , 8 6}$ ha & $\mathbf{2 9 , 2}$ ha \\
\hline
\end{tabular}

Em contrapartida, no ordenamento espacial do AR; descontando-se a área cedida para a DESO, apenas as áreas de PP ao longo de cursos d'água com menos de $10 \mathrm{~m}$ foram computadas, tendo-se apenas 10,86 ha de áreas de PP, equivalente a 1,2\% da área do AR (INCRA, 2009). E, neste estudo, considerando a base cartográfica utilizada (SERGIPE, 2012) e o levantamento de campo, observa-se 22,5 ha e 6,7 ha de áreas de PP ao longo dos cursos d'água e no entorno das nascentes, respectivamente, ou seja, 3,2\% da área do AR. Estas diferenças observadas se devem, especialmente, à reclassificação realizada no momento do planejamento ambiental do AR; em que parte das áreas de PP foram incorporadas às áreas de RL, bem como, a omissão das áreas de PP presentes nas parcelas agrícolas. Ainda, têm-se as áreas de PP inseridas na área do reservatório da barragem que foram excluídas do AR. Com relação ao indicador Área de RL, cita-se que, o imóvel, à época da fiscalização, não possuía RL, sendo posteriormente delimitada e registrada pelo INCRA, durante a fase de licenciamento ambiental (Licença de Instalação e Operação). Atualmente, consta de uma área total de 532,41 ha, segmentada em três glebas (RL I, RL II e RL III), equivalente a $57,7 \%$ da área do $A R$ (INCRA, 2009); muito superior ao percentual (20,0\%) determinado na legislação ambiental (BRASIL, 2012).

Por conseguinte, comumente, destina-se áreas para $\mathrm{RL}$, de pouca cobertura vegetal e importância para o equilíbrio ecológico global da área (MAZZETTO, 2000). Neste AR, as áreas de RL com vegetação nativa $(47,7 \%)$ equivalem a $27,5 \%$ da área do AR, e, o indicador Área de Vegetação Nativa mostra que o AR possui $48,1 \%$ da área ambiental com cobertura de vegetação nativa, refletindo o caráter ambiental da reforma agrária e disponibilidade de serviços ecossistêmicos, para além dos serviços de abastecimento (produção de alimentos, fibras e madeira).

Ressalta-se ainda que, o percentual de áreas ambientais (PP+RL) é superior $(60,9 \%)$ à soma das áreas de uso agrícola e do núcleo urbano do AR. Estas áreas são compostas por vegetação nativa do bioma Mata Atlântica, classificadas como Floresta Estacional Decidual, previamente protegida pela Lei nº 11.428/2006; a 
Lei da Mata Atlântica (BRASIL, 2006). Desta forma, observa-se que, o INCRA, aproveitando-se desta restrição já imputada pela citada lei, destinou estas áreas para comporem RL coletiva, ou seja, não estão inseridas nos lotes produtivos; procedimento importante para a redução do passivo ambiental (SOARES, 2008).

É importante ressaltar que o uso do solo refletirá na vida útil da barragem do Rio Poxim-Açu, devido à geração de sedimentos a serem potencialmente carreados ao perímetro da barragem, pois esta é circundada pelo AR, especialmente pelas áreas ambientais. Dechen et al. (2015) comentam que a erosão hídrica é uma das principais formas de degradação dos solos no Brasil e um dos mais significativos fatores que afetam negativamente os recursos hídricos, pois a perda de sedimentos provoca o assoreamento de mananciais no meio rural, comprometendo a qualidade da água e reduzindo as vazões médias dos rios e reservatórios (AGUIAR JUNIOR et al., 2015). E, por fim, quanto à subcategoria 'Ações de Valorização', apesar deste AR possuir, à época (ano 2015), acompanhamento de técnicos da Assessoria Técnica, Social e Ambiental à Reforma Agrária (ATES), não foram observadas ações ambientais, bem como se verificou a ausência de propostas de proteção, a exemplo de cercamento das áreas de RL.

Assim, percebe-se que os indicadores selecionados podem ser aplicados na análise e monitoramento das áreas ambientais de ARs, por meio de imagens disponíveis e gratuitas (Google Earth). Entretanto, a utilização de indicadores métricos de paisagem, em plataforma SIG, necessitam de imagens com boa resolução e acurácia do analista para o seu processamento. Quanto aos indicadores qualitativos, podem ser obtidos, facilmente, no banco de dados do gestor do AR, desde que esteja atualizado. E ainda, com a obrigatoriedade da inserção dos ARs no CAR, pode-se potencializar a utilização desses indicadores como ferramentas para a gestão ambiental dos ARs.

\section{CONCLUSÕES}

De forma geral, a utilização dos indicadores de paisagem da categoria 'Usos da Terra', no modelo DPSIR, é importante para a avaliação e o monitoramento das áreas ambientais em ARs, mostrando-se uma ferramenta efetiva para a gestão ambiental de ARs. E, de forma específica, no estudo de caso realizado no AR Rosa Luxemburgo II, em São Cristóvão, Estado de Sergipe, permite-se concluir que: Na fase de ordenamento espacial do AR, existe significativa omissão das áreas de PP e das nascentes; Os percentuais observados de áreas efetivamente ocupadas com vegetação nativa nas áreas ambientais, alerta para a necessidade de sua recomposição florestal, a fim de disponibilizar plenamente os serviços ecossistêmicos; A existência da ATES não representou ações ambientais de conservação e de proteção das áreas de PP e RL.

\section{REFERÊNCIAS}

AGUIAR JUNIOR, T. R.; PARRON, L. M.. Indicadores de serviços ambientais hídricos e a contribuição da vegetação ripária para a qualidade da água. In: PARRON, L. M.; GARCIA, J. R.; OLIVEIRA, E. B.; BROWN, G.; PRADO, R. B.. Serviços ambientais em sistemas agrícolas e florestais do Bioma Mata Atlântica. 1 ed., Brasília: EMBRAPA, 2015. p.183-190. classification framework. Ecological Indicators, v.83, p.96102, 2017. DOI: http://dx.doi.org/10.1016/j.ecolind.2017.07.023

BORGOGNO-MONDINO, E.; FABIETTI, G.; AJMONE-MARSAN, F.. Soil quality and landscape metrics as driving factors in a multi-criteria GIS procedure for peri-urban land use planning. Urban Forestry \& Urban Greening, v.14, n.4 
p.743-750, 2015. DOI:

https://doi.org/10.1016/i.ufug.2015.07.004

BRASIL. Lei n 12.651: Dispõe sobre a proteção da vegetação nativa e dá outras providências (Novo Código Florestal). Brasília: Diário Oficial da União, 2012.

BRASIL. Lei no 11.428:Dispõe sobre a utilização e proteção da vegetação nativa do Bioma Mata Atlântica e dá outras providências. Brasília: Diário Oficial da União, 2006.

CUNHA, B. G.; PEDROTTI, A.. Serviços ambientais (ecossistêmicos) em Assentamentos Rurais. In: SOARES, M. J.. Pesquisas ambientais em foco. Aracaju: Criação, 2015. p.237-252.

CUNHA, B. G.; LORETO, M. D. S.; SCHAEFFER, C. E. G. R.. Ambientes e usos no Projeto de Assentamento São Francisco, Buritizeiro, Minas Gerais. In: SIMPÓSIO INTERNACIONAL DE GEOGRAFIA AGRÁRIA, 6. Anais. João Pessoa: UFPB, 2013.

CUNHA, L. H.; NUNES, A. M.. Nature protection and environmental conflicts in rural settlements. Desenvolvimento e Meio Ambiente, Curitiba, n.18, p.27-38, 2008. DOI: http://dx.doi.org/10.5380/dma.v18i0.13422

CASSATELA, C.; VOGUERA, A.. Indicators used for landscapes. In: CASSATELA, C.; PEANO, A.. Landscape Indicators: Assessing and Monitoring Landscape Quality. Nova York: Springer, 2011. p.31-46.

COElHO, I. A. M.; DUARTE, S. M. A.; COELHO, O. A. M.. Study of the dynamics of vegetation cover in the city of Forest / PE through digital image processing. Revista GEAMA, Recife, v.1, n.2, p.187-204, 2015.

COSTA, C. C.; GOMES, L. J.; ALMEIDA, A. P.. Selection indicators of sustainability in the Atlantic Forest fragments in basin hydrographic River Poxim through the geoprocessing.

REGET, v.18, n.1, p.209-219, 2014. DOI:

http://dx.doi.org/10.5902/2236117011248

DAILY, G.. Nature's services: societal dependence on natural ecosystem. Washington: Island Press, 1997.

DECHEN, S. C. F.; TELLES, T. S.; GUIMARAES, M. F.; MARIA, I. C.. Losses and costs associated with water erosion according to soil cover rate. Bragantia, Campinas, v.74, n.2, p.224-233, 2015. DOI: http://dx.doi.org/10.1590/1678-4499.0363

DIAS, M. M.. Extensão rural para agricultores assentados: uma análise das boas intenções propostas pelo 'Serviço de Ates'. Cadernos de Ciências e Tecnologias, Brasília, v.21, n.3, p.499-543, 2004.

FERREIRA, R. A.; AGUIAR NETTO, A. de O.; SANTOS, T. I. S.; SANTOS, B. L.; MATOS, E. L.. The sub-basin springs of Poxim river, state of Sergipe: the degradation to restoration. Revista Árvore, Viçosa, v.35, n.2, p.265-277, 2011. DOI: http://dx.doi.org/10.1590/S0100-67622011000200011

FREITAS, E. P.; MORAES, J. F.; PECHE FILHO, A.; STORINO, M.. Indicadores ambientais para áreas de preservação permanente. Revista Brasileira de Engenharia Agrícola e Ambiental-Agriambi, Campina Grande, v.17, n.4, p.443-449,
2013. DOI: http://dx.doi.org/10.1590/S141543662013000400013

KEMERICH, P. D. C.; RITTER, L. G.; BORBA, W. F.. Indicators of environmental sustainability: methods and applications. Revista do Centro do Ciências Naturais e Exatas - UFSM, Santa Maria, v.13, v.5, p.3723-3736, 2014. DOI: http://dx.doi.org/10.5902/2236130814411

IBGE. Instituto Brasileiro de Geografia e Estatística. Divisão territorial do Brasil em mesorregiões e microrregiões geográficas. Rio de Janeiro: FIBGE, 1990.

INCRA. Instituto Nacional de Colonização e Reforma Agrária. INCRA nos Estados: informações gerais sobre os assentamentos rurais de reforma agrária. 2017.

INCRA. Instituto Nacional de Colonização e Reforma Agrária. Processo Administrativo de Criação do Projeto de Assentamento Rural Rosa Luxemburgo II, São Cristóvão, Sergipe. 2009.

INCRA. Instituto Nacional de Colonização e Reforma Agrária. Processo Administrativo de Fiscalização da Fazenda Poxim, São Cristóvão, Sergipe. 2005.

LANDIS, J. R.; KOCH, G. G.. The measurements of observed agreement for categorical data. Biometrics, v.33, n.1, p.159174, 1977.

LIRA, W. S.; CÂNDIDO, G. A.. Análise dos modelos de indicadores no contexto do desenvolvimento sustentável. Revista Perspectivas Contemporâneas, Campo Mourão, v.3, n.1, p.31-45, 2008.

MAZZETTO, C. E. S.. Sustentabilidade Ambiental e Gestão do Uso da Terra: uma abordagem voltada aos Assentamentos de reforma agrária. Revista Informe Agropecuário, Belo Horizonte, v.21, n.202, p.120-126, 2000.

MENDES, I. S.; MERCANTE, E.; SCARIOTTO, M. C.; MAGGI, M. F.; CORREA, M. M.; KUSMINSKI, D.. Geoprocessing applied to the physiographic characterization of the Lontras River Basin. Revista Geama, v.2, n.3, p.249-254, 2016.

MEA. Millenium Ecosystem Assessment. Ecosystem and human well-being: synthesis. Washington: Island, 2005.

NEVES, M. A.; MACEDO, L. C. B.; FONSECA, L. C.; ALVES, J. P. $H$.. Reservoir water quality Jaime Umbelino - dam Poxim/Sergipe. Interfaces Científicas - Saúde e Ambiente, Aracaju, v.5, n.1, p.81-94, 2016. DOI: https://doi.org/10.17564/2316-3798.2016v5n1

NIEMEIJER, D.; GROOT, R. S.. A conceptual framework for selecting environmental indicator sets. Ecological Indicators, v.8, p.14-25, 2008. DOI: https://doi.org/10.1016/j.ecolind.2006.11.012

ONDETTI, G. The social function of property, land rights and social welfare in Brazil. Land Use Policy, v.50, p.29-37, 2016. DOI: https://doi.org/10.1016/j.landusepol.2015.08.028

PHILLIPS, A; LOWE, K. W.. Prioritising Integrated Landscape Change Through Rural Land Stewardship for Ecosystem Services. Australasian Journal of Environmental Management, v.12, (Supplementary Issue), p.39-47, 2005. 
QGIS. Development Team: QGIS Geographic Information System. Open Source Geospatial Foundation Project. 2017.

SERGIPE. Secretaria de Estado do Meio Ambiente e dos Recursos Hídricos. Atlas digital sobre recursos hídricos. Aracaju: SEMARH, 2012.

SILVA, E. B.; NOGUEIRA, R. E.; UBERTI, A. A. A.. Land suitability evaluation as subsidy to the settlement of rural famylies, using geographic information system. Revista Brasileira de Ciência do Solo, Viçosa, v.34, n.6, p.1977-1990, 2010.

SOARES, J. L. N.. The territorial organization of rural settlements to achieve the environmental legislation in the amazon region. Campo-território: Revista de Geografia Agrária, v.3, p.143-155, 2008.

SVARSTAD, H.; KJERULF, L.; ROTHMAN, D.; SIEPEL, H.; WA, F. Discursive biases of the environmental research framework
DPSIR. Land Use Policy, v.25, p.116-125, 2008. DOI: https://doi.org/10.1016/i.landusepol.2007.03.005

VILAR, M. B.; JACOVINE, L. A. G.; OLIVEIRA, A. C. C.; JACON, A. D.; SANTOS, M. O.; SOUZA, A. L.. Incentivo ao manejo de bacias hidrográficas pelo pagamento por serviços ambientais. Informe Agropecuário, Belo Horizonte, v.32, n.263, p.30-40, 2012.

VOGHERA, A.. Land Use Indicators for Landscape Assessment. In: CASSATELLA, C.; PEANO, A.. Landscape Indicators: Assessing and Monitoring Landscape Quality. Nova York: Springer, 2011, p.141-164.

YANBO, Q.; JIANG, G.; ZHAO, Q.; MA, W.; YANG, Y.. Geographic identification, spatial differentiation, and formation mechanism of multifunction of rural settlements: A case study of 804 typical villages in Shandong Province, China. Journal of Cleaner Production, v.166, Supplement C, p.1202-1215, 2017. DOI:

https://doi.org/10.1016/j.jclepro.2017.08.120

A CBPC - Companhia Brasileira de Produção Científica (CNPJ: 11.221.422/0001-03) detém os direitos materiais desta publicação. Os direitos referem-se à publicação do trabalho em qualquer parte do mundo, incluindo os direitos às renovações, expansões e disseminações da contribuição, bem como outros direitos subsidiários. Todos os trabalhos publicados eletronicamente poderão posteriormente ser publicados em coletâneas impressas sob coordenação da Sustenere Publishing, da Companhia Brasileira de Produção Científica e seus parceiros autorizados. Os (as) autores (as) preservam os direitos autorais, mas não têm permissão para a publicação da contribuição em outro meio, impresso ou digital, em português ou em tradução. 